\title{
A Star is Born? The Authors, Principles and Objectives of Analytical Sociology
}

\section{Filippo Barbera}

University of Turin. Department of Social Sciences

filippo.barbera@unito.it

\begin{abstract}
This article presents the main features and objectives of the so-called «social mechanisms based explanation» or "analytical sociology». This perspective has gained quite considerable attention in contemporary debate, both for its theoretical novelty as well as for its empirical results. In the first part of the article I describe the key concepts, main scholars and institutional strengths of this approach. In the second part, I clarify the relationships between the analytical sociology perspective and the main trends in contemporary sociology, both theoretical and empirical. In the third part, three core principles of the approach are outlined: the idea of causal process, the relevance of multilevel theory and the prominence of formal theories and models.
\end{abstract}

Key words: analytical sociology, explanation, methodological individualism, emergent effects, theory and research.

Resumen. ¿Ha nacido una estrella? Autores, principios y objetivos de la sociología analítica

Este artículo presenta los principales rasgos y objetivos de la así llamada «explicación basada en mecanismos sociales» o "sociología analítica». Esta perspectiva ha ganado considerable atención en los debates contemporáneos, tanto por su novedad teórica como por sus resultados empíricos. En la primera parte del artículo se pasa revista a los conceptos centrales, los principales estudiosos y los pilares institucionales de este enfoque. En la segunda parte, se clarifican las relaciones entre la perspectiva de la sociología analítica y las principales corrientes de la sociología contemporánea, tanto teóricas como empíricas. En la tercera parte, se esquematizan tres principios básicos del enfoque: la idea de procesos causales, la relevancia de la teoría multi-nivel, y la preeminencia de las teorías y modelos formales.

Palabras clave: sociología analítica, explicación, individualismo metodológico, efectos emergentes, teoría e investigación.

\section{Contents}

\section{Introduction}

2. Analytical sociology in contemporary debate

3. The relationship with social theory and with other trends in contemporary sociology
4. The relationship with empirical research

5. Analytical sociology: some leading principles

Conclusions

Bibliography 


\section{Introduction}

Recent debates point to the consolidation of a theoretical and empirical perspective that has become increasingly established in contemporary sociology. Many terms have been used to describe it, including: «explanation through social or generative mechanisms», "sociology of causal processes», "sociological analysis» and "analytical sociology». These notes aim to illustrate the main characteristics of this approach — revealing its true core and isolating some principles and general objectives, without venturing into a systematic comparison with other currently adopted sociological approaches ${ }^{1}$.

Before we tackle the matter, it is worth clarifying the meaning of the adjective "analytical», by referring to the definition provided in the "manifesto" of this approach (cf. Hedström 2005). The salient characteristic of analytical sociology consists in the defence of reasoning explicitly in terms of theoretical models: realistic abstractions that are capable of grasping the generative forces of the phenomenon being studied and, as a result, explaining it in a satisfactory manner. The realistic models used by analytical sociology also must be open to empirical test, thus facilitating integration between the production of the theory and the moment of empirical research ${ }^{2}$.

The article is structured as follows. The initial introductory part provides an outlined presentation of the approach and of its key concepts, main authors, analytical objectives and institutional dimensions. The second part offers a schematic overview of the differences between analytical sociology and recent trends in current theoretical debate, while also examining the interactions between analytical sociology and empirical research. The third and last part concludes by pinpointing the key principles that together form the basic core of this approach.

\section{Analytical sociology in contemporary debate}

From the viewpoint of the history of ideas, analytical sociology is heir to Merton's middle-range sociology (Hedström and Swedberg 1998, 4-7). With this it shares the idea that theories are above all instruments that help to explain -rather than conceptual constructions, visions of the world, or ethical judgements - and that close interaction between theory and empirical research must always be placed at the very heart of scientific work. In the 1970s, the

1. This decision is not made without a certain cost. The most obvious is that it focuses - one might say - specifically on the strong points of explanation through mechanisms, without considering its limitations, except in the most coincidental manner.

2. One specification of this argument maintains that analytical approaches use the economic explanation (rational choice and minimal model of social structure) as the «zero model» to which further elements - both agent-based and structural — are gradually added, according to what Siegwart Lindenberg has referred to as the «method of decreasing abstraction» [1992]. At the same time, it has been noted that analytical sociology requires realistic -altough incomplete - assumptions, both from psycological and sociogical viewpoints [cf. Hedström 2005]. 
so-called crisis of «determinist paradigms» (Boudon 1979a) focused attention on the quest for microfoundations of sociological explanation. In this context, the works of James S. Coleman (1986), Raymond Boudon (1979b) and Jon Elster (1983) were of key importance to set up the core principles of mechanisms-based sociological explanation.

The recent attention that has been paid to social mechanisms can be discerned in some key contemporary works (Hedström and Swedberg 1998; Blossfeld and Prein 1998; Goldthorpe 2000; Hedström 2005). Some of these show how the idea of mechanisms-based explanation was already present in the classic works of sociology (Boudon 1979a; Coleman 1986; Cherkaoui 2000; Elster 1985). Notwithstanding the heterogeneity in the debate on social mechanisms explanation ${ }^{3}$ all the interpretations agree on one important point: the greatest obstacle to the generative mechanisms perspective has been the influence of the positivist concept of explanation (Cherkaoui 2000, 131-134; Goldthorpe 2000, chap. 12) ${ }^{4}$.

Cherkaoui ( ibid) sums up this influence in four points: first, the absence of explicit references to non-observable processes and dimensions (desires, beliefs, reasons, intentions, etc.); second, the tendency to explain through laws or nomological regularities; third, the refusal to search for the causes or generative mechanisms of social phenomena - branded as having metaphysical velleities - in favour of a vision of science as an empirical analysis of functional relationships among variables; fourth, the conviction that the ultimate aim of science is reformatory action and that only predictive knowledge - rather than explanation- can permit the intervention of man in society. From the positivist perspective, explanation thus means finding the laws that regulate the functional relationships between phenomena, deriving them from other more general laws.

The social mechanisms perspective, on the contrary, attributes a special role to explanation as opposed to prediction, and a central mission to the idea of generative causality: in other words, to causal processes, whether observable or not, which explain why and how a certain phenomenon has been generated. Very basically, a mechanism is therefore a causal process through which a particular phenomenon is generated. The generative mechanisms and the phenomenon to be explained are located on different levels and the explanation works only in certain contextual conditions.

For example: the phenomenon to be explained may be the constant relationship between the pressure, volume, and temperature of a gas: PV = T i.e.

3. Mahoney [2001]identity twenty-four definitions of «social mechanisms» and he groups them in three categories: (i) mechanisms as interviening variables, (ii) mechanisms as theoretical hyphotesis, (iii) mechanisms as unobserved entities able to operate as generative forces of the empirically observed phenomena.

4. Beside the influence of positivism, others and somehow opposite factors must obviously be added. Among these the "critical» and "expressive» inclination of sociology played certainly an important role in preventing the development of a sound explanatory sociology. I will briefly analyze this matter later on in the article. 
$\mathrm{PV} / \mathrm{T}=$ constant. This relationship illustrates the variation of each factor in relation to the other two, but it says nothing about the mechanisms that explain the observed relationship (ibid). The explanation is achieved with the causal process or mechanism that explains the relationship between the temperature, pressure and volume of the gas. In other words, the mechanism is to be found in the generative processes that are located on a lower level and that are postulated by kinetic molecular theory. The molecules generate an increase in pressure by "pressing" against the walls of the gas and this - by means of the kinetic energy that is developed-also brings about a rise in temperature. More generally: «The basic structure of hyphoteses-making takes the form of speculating upon the generative mechanisms that give rise to observable outcome patterns» (Pawson 2000, 296).

In terms of mechanisms-based explanation, the macro-phenomenon is explained by a simplified representation of the micro-processes: the molecules are in fact represented as though they were «spheres». This simplification is acceptable in that it makes it possible to explain the functional relationship observed, even though it does not explain in detail or with precision the dynamics of the individual molecules that make up the gas: "the mechanism must produce interesting hypotheses or explanations at the higher level, without complex investigations at the lower level» (Stinchcombe 1993, 27). In addition, the mechanism works in certain conditions: for the example, the process does not work as indicated when the temperature of the gas is very low (Pawson 1997, 59).

Analytical sociology resorts to a similar idea: explaining means finding generative micro-processes that explain the macro-phenomenon observed, attempting to render explicit the conditions that enable the mechanisms to "function» as hypothesised. This translates into the formulation and empirical testing of hypotheses concerning actions and interactions in particular institutional conditions and in the presence of particular interdependency structures connecting the action units being considered (Boudon 1979a; Coleman 1986; Cherkaoui 2000).

In contemporary debate, the convergence towards explanation through mechanisms involves theoretical sociologists (Jon Elster, Raymond Boudon, Siegwart Lindenberg) and leading names in quantitative research ${ }^{5}$ (John H. Goldthorpe, Hans P. Blossfeld). Then, alongside supporters of methodological individualism (Raymond Boudon, Diego Gambetta, Peter Hedström) and of rational choice (M. Hechter, D.D. Heckathorn), we also find some sociologists influenced by structuralist perspectives (Aage Sørensen). But there are also representatives of mathematical sociology (Peter Abell, Christofer Edling), supporters of simulative methods (Michael Macy) and historically oriented sociologists (Edgar Kiser). Despite the theoretical differences, the distinct methodological preferences, and the study of various empirical matters, it can

5. Important qualitative sociologists have also shown interest in the mechanisms perspective, particularly to setting extensive variables-based research against intensive cases-based research [Ragin 1998, 165-167] and emphasising the possibility of building up formalised narratives of social processes [Abell 1987]. 
Table 1. A guide to analytical sociology.

Key authors: P. Abell, H.P. Blossfeld, R. Boudon, R. Breen, C. Edling, J. Elster, H. Esser, T. Fararo, D. Gambetta, J.H. Goldthorpe, M. Hechter, D.D. Heckathorn, P. Hedström, G. Hernes, S. Lindenberg, M.W. Macy, K.-D. Opp, W. Raub, A. Sørensen, A.L. Stinchcombe, R. Swedberg, A. van den Berg.

Basic approach: Explanation of macro-phenomena by means of modelling and empirical testing of defined generative micro-processes.

Key concepts: "Explanation», "generative mechanisms», "formal models», «microfoundations», "social structure», «social dynamics».

Main areas of interest: Social mobility and inequalities, careers, organisational dynamics, labour market, social change, political behaviour, diffusion of social phenomena, social regulation of the economy, collective action and social dilemmas. Most important institutions: Dept. of Sociology ,University of Stockholm; Oxford University; ISCORE inter-university consortium, Universities of Nimega, Utrecht and Groningen; Dept. of Sociology, Cornell University; Gemas, University of Paris-Sorbonne.

Most influential works: J.S. Coleman, Foundations of Social Theory, [1990]; J. Elster, Nuts and Bolts for the Social Sciences, 1989; P. Hedström, Dissecting the Social: On the Principles of Analytical Sociology [2005]; R. Boudon, [1984] La place du désordre; J.H. Goldthorpe, On Sociology [2000]; P. Hedström and R. Swedberg [ed's.] [1998] Social Mechanisms; H.P. Blossfeld and G.Prein [eds.] [1998] Rational Choice Theory and Large Scale Data Analysis; L. Udehn [2001] Methodological Individualism; D. Gambetta [1990] Were They Pushed or Did They Jump?, D. Little [1998], Microfoundation, Methods and Causation.

reasonably be said that there is a common approach, which can be summed up in the expression analytical sociology. The consistency of their intellectual output and the intensity of their institutional exchanges confirm that this is a group of scholars who share common objectives ${ }^{6}$. Table 1 provides a summary of some of the main theoretical and institutional dimensions of this current in contemporary sociology.

Quite apart from the «institutional» aspects of analytical sociology, it is worth expanding on some elements shown in the above table, in order to clarify the content of this approach. The principle mission of mechanisms-based explanation may be grasped by recalling the objectives that - according to Boudon (2002) — characterise sociology tout court. Sociology is said to have cognitive or scientific objectives (explaining phenomena), descriptive objectives (providing information on phenomena for policy purposes), expressive objec-

6. The recent foundation of the EAS (European Academy of Sociology) [Lindenberg 2002] is a sort of institutionalisation of analytical sociology. Members of the EAS not included in Tab.1 are: Andreas Diekmann, Robert Eriksson, Ehrard Frieberg, Jürgen Friedrichs, Anthony Heat, Karl Ulrich Mayer, Trond Petersen, Luca Ricolfi, Wolfgang Schluchter, Ole-Jörgen Skog, Frans Stokman, and Woult Ultee. 
tives (arousing emotions in the reader) and critical objectives (achieving emancipation of people). In fact - even though Boudon does not put that much emphasis on it- these are ideal-typical distinctions: sociologists' works are characterised by the coexistence of more than one objective, and this is true also for those who start out from analytical sociology. In particular, this can be seen in the coexistence of cognitive and descriptive aims and in the fact that less attention is paid to expressive and critical objectives ${ }^{7}$.

The reciprocal play of description and explanation has some positive consequences for the development of knowledge. Goldthorpe (2000, chap. 5), for example, maintains that scientific progress often comes from good descriptions that highlight new, non-intuitive phenomena, which in turn solicit the formulation of new concepts and theories in order to be explained. Here Goldthorpe takes his cue from Merton, who points out that before explaining or interpreting the phenomenon, it is necessary to establish that it exists and that it demonstrates sufficient regularity to require and permit an explanation (Merton 1987, 2).

So before explaining the phenomenon, it is necessary to provide a good description of it, making sure of its space-time stability, of its non-spurious nature, and that it is not the result of errors in observation protocols. Otherwise one runs the risk of «explaining» pseudo-facts, and research based on pseudofacts - continues Merton- leads to pseudo-problems. Goldthorpe (2004) maintains that descriptions are good in as much as they draw attention to phenomena that are not self-evident in the daily life, and whose explanation requires the introduction of plausible generative mechanisms. The systematic collection of census data, for example, has made it possible to reveal previously unknown, non-intuitive configurations of social phenomena: new observation instruments thus lead to new knowledge (ibid). Besides, it is a one-to-one relationship: good empirical descriptions require adequate theoretical input. Taking care not to explain pseudo-facts must not lead to the erroneous opposite extreme of creating arte-facts based on statistical models with a high $N$ (Hedström 2005). In other words, computational parsimony should not be confused with theoretical parsimony: "There is nothing sociologically parsimonious about a model with 10 to 20 independent variables lined up to control each other. There is no known sociological theory that will justify such a model» (Sørensen 1998, 243).

All in all, there are some perspectives in analytical sociology — such as those illustrated by Raymond Boudon or Peter Hedström — which are more interested in the "pure» cognitive aspects of the scientific undertaking, while others, such as those of John H. Goldthorpe or Richard Breen, pay closer attention to the continuous interaction between descriptive sociology and cognitive sociology (cf. also Coleman 1990, 610-649). Both positions, as we shall see, are equally critical of the main currents of contemporary sociology.

7. As pointed out by Goldthorpe in his «third annual lecture» for the European Academy of Sociology (25.10.2003, Paris) (cf. Goldthorpe 2004). 


\section{The relationship with social theory and with other trends in contemporary sociology}

Analytical sociology tends more than anything to mark out clear borders with the so-called «social theory». This is identified with the continuing creation of "conceptual labels» (Hedström and Swedberg 1998, 1-2) or with the tendency to adopt a «books about books» approach (Goldthorpe 2000, 1-5). In the words of van den Berg: «More and more, it seems, what passes for "sociological theory» [...] deals with matters of epistemology, ontology, and philosophy of science, at the expense of the more mundane business of theorizing about the social world» $(1998,205)$. In other words, contemporary social theory has explicitly and consciously abandoned the objective of explanation, thus weakening the integration of theory and empirical research to an unacceptable extent.

According to its most prominent supporters, social theory is actually intent on «discourse» rather than on explanations, and should mainly concentrate on the meta-criteria of the truth of theories - rather than on their concrete explanatory power - with the aim of conceptualising the nature of social activity, rather than its explanation. These characteristics are the result of an objective that is common to contemporary "social theoreticians» and that is as ill-concealed as it is precise: the search for the "Great Synthesis». This produces stunning «theoretical» structures, so packed with neologisms and circumlocutions as to require the use of special glossaries. It often leads to the creation of theoretical instruments which are so complicated as to prevent empirical analysis, or to make it possible only in an indirect and extemporary manner.

Many contemporary social theories have aimed to go beyond Parsons's attempt at synthesis but, ironically, the great conceptual structures that have been produced do not appear to be all that different from the frameworks of American structural-functionalism. This point has been very effectively summed up by Axel van den Berg (ibid), to whom reference is made for further details. The crux of the matter can be expressed by the idea that contemporary social theory has given itself overly ambitious objectives, such as: "going beyond the borderlines between objectivism and subjectivism", "clarifying the relationship between action and structure» and "overcoming the mono-dimensional character of partial theories». It is indeed a bit hard to believe that it should be for sociologists to provide a theoretical solution to the dualisms and antinomies that have been characteristic of Western thought ever since its origins. As a logical consequence of this trend — as far as we are concerned here- the impact of social theory on empirical research has been very limited ${ }^{8}$.

8. A more useful idea is that theorising at a high level of abstraction may be useful as an initial stimulus for sociological imagination. This however does not mean that efforts need to be channelled towards the search for a "great synthesis", and it also prevents the primary object of the sociological undertaking from becoming the theory or the thoughts of a single author. 
The difference that separates analytical sociology from radical post-modernism is also absolutely clear. The main criticisms can be summed up in the idea that the radical wing of this movement has prematurely and unjustifiably declared the impossibility of sociology as a social science, in favour of an exclusively critical vision of the discipline, while leaving no room for other approaches. For example, according to the positions adopted by radical post-modernism, the application of the theory of rational choice in sociology leads inevitably to the exclusion of its supporters from sociological debate (Denzin 1990, 506). $\mathrm{Or}$, as we can read in a recent work that is favourable to critical sociology, maintaining that sociology has not been and can never be a science (Flyvbjerg 2001, p. 9-49) is not exactly a great example of «pluralism in action». Radical and de facto anti-pluralist positions, such as those expressed by Denzin and Flyvbjerg, help poison the debate and provoke reactions, which are equally tough and provocative, such as those of Goldthorpe (2000, 69, note).

Lastly, analytical sociology also differs from the tendency of contemporary sociology to engage in the production of artificial images of society, by constantly resorting to allusive terms and neologisms such as "risk society", "globalism», "reflective modernisation», "network society», "radical modernity», «surmodernity», «liquid modernity», etc. The production of images of the world, with mainly critical or expressive objectives, is not in itself alien to sociological tradition. But it is worth remembering that one of the most impelling images, and one with the greatest possible consequences for modern sociology -Max Weber's «iron cage»-comes from a careful analysis of the historic and economic trends of emerging capitalism. More than anything, it is a representation produced during a life devoted to sociological knowledge and not - as is increasingly the case in contemporary sociology- a new «epoch-making» vision of «society» that comes out once a month, often produced with little regard for thoroughness in its reasoning (cf. Abell 2001a).

The response of analytical sociology to the limits of the most important «theoretical» trends in contemporary sociology do not simply consist in passionate references to the importance of «empirical research». Blind empiricism is indeed no more than a disorderly reaction to abstract theorising - and it is no less absurd (van den Berg 1998, 206).

\section{The relationship with empirical research}

From the perspective of social mechanisms, «variable sociology» represents the macro-outcomes of interesting phenomena, but not the processes which have produced them: this means that from a explanatory viewpoint, it is a blackbox analysis that needs to be completed with hypotheses and empirical tests relating to the mechanisms that produce the statistical relationship observed (Hedström and Swedberg 1998).

Both Coleman $(1964,518)$ and Boudon $(1976,117)$ have pointed out that variables-based models do not explain the relationship being examined, but simply summarise it in a clear manner. The explanation of the relationship 


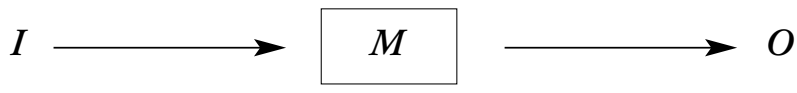

Figure 1. The black-box model.

From Hedström and Swedberg $(1998,9)$.

is achieved by means of a theory or a model that: «includes the observed empirical structure as one of its consequences» (Boudon 1979b, 51-52).

In standard quantitative analysis — as suggested by scholars who has always practised and strenuously defended it (Goldthorpe 2000, 33) - there is no systematic effort to show how the relationship between variables is produced by precise social mechanisms. On the contrary, this is a particular advantage of those theoretical models that possess an analytical structure that makes it possible to deduce the general form of the relationships that will need to be estimated or verified at the empirical level (Ricolfi 1984, XII). In other words, analytical sociology suggests that quantitative research might be made more effective by concentrating the analysis on the causal processes rather than exclusively on the causal effects (Hedström 2001). This means producing and testing theoretical models that represent substantive processes capable of generating the phenomenon that is empirically observed. On the other hand, the role of theory in variable sociology is said to be limited to specifying which variables are to be introduced into the equation and to specifying how these variables are connected one to the other, adopting the simplest statistical models, or those that are easiest to interpret as "default models» (cf. Sørensen 1998). In the «variables-based» model the search for the most effective explanations is consequently achieved by adding information inside the black box.

In the mechanisms-based explanation, on the contrary, the explanatory power of the model increases the more one represents and tests substantive processes theoretically capable of producing the phenomenon as the data concisely describe it. Mathematical modelling has —amongst others - this objective (ibid).

The model (mathematical or based on simulation) 9 acts as a "bridge» between sociological theory and empirical research: the unbroken lines in Figure 2 represent the first route: theory $\rightarrow$ models $\rightarrow$ statistical estimate of the parameters, while the broken lines indicate the feedback process: empirical results $\rightarrow$ models $\rightarrow$ theory.

The first step consists in formalising the theory being examined, and today sociologists have at their disposal instruments to model many of the concepts and theories commonly used in sociology. In other words, there are models of

9. Agent-based modelling is a useful tool for modelling complex (non-linear) generative processes. 


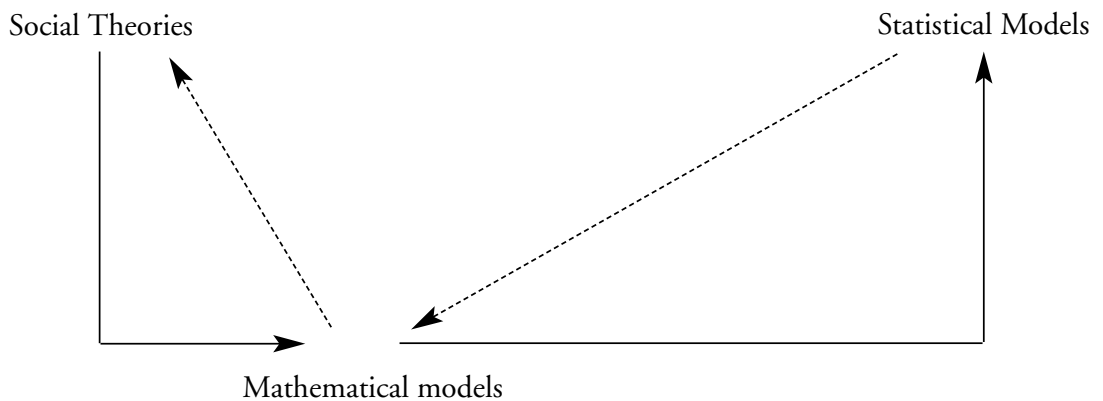

Figure 2. Modelling as a bridge between theory and empirical research.

From Bäckman and Edling (1999, 70).

processes, models of structures and models of actions and interactions (Edling 2002). The parameters of the theoretical model "translated» into a mathematical or simulative format can thus be estimated using the most suitable statistical analysis. Lastly, and only at this point, it is possible to verify the hypothesis and make a substantive interpretation of the model (broken-line arrow). The relationship between mathematical/simulative model and sociological theory requires good theoretical inputs: without a good theory there can be no good model. As a result: «if the sociological theory is poor, it will certainly not be improved by applying a sophisticated mathematical model» (Bäckman and Edling 1999, 70) ${ }^{10}$.

The position adopted by analytical sociology vis-a-vis qualitative sociology is less easily defined. One point however appears to be agreed upon: qualitative research has to tackle the same problems as those faced by quantitative research and cannot - on the basis of some special epistemological licenserefuse at least to measure itself explicitly against the «classic» problems of social research. And in the view of some scholars, this means also adopting the same solutions used in quantitative research, while, for others, the recognition of common problems does not imply acceptance of these solutions.

Goldthorpe's position with regard to ethnography is a good example of the first position (2000, chap. 4). In the view of the English sociologist, much of contemporary ethnography refuses to face up to the logic of inference ${ }^{11}$ which — according to an influential perspective (cf. King, Kehoane and Verba 1994) governs all sociological research. Social ethnography, particularly in the current influenced by the post-modern debate, does not take into adequate consideration the scientific problem of inference, and this prevents to analyze both «variation within objects» and «between objects», as well as «problems of con-

10. For examples of empirical research in this vein, see Sørensen [1977] and Hedström[1994].

11. In other words, to the logical rules that connect empirical evidence with the subject - causal or descriptive - that derives from it. 
text». Leaving aside the details of the matter — for which reference is made to Goldthorpe's text - the crucial point is that, before attempting to establish ethnography as a separate method governed by a form of logic and rules that break with the classical tradition of social study, it is necessary to consider the methodological solutions offered by quantitative tradition. According to Goldthorpe, this should lead to a closer consideration of the forms of probabilistic sampling in the process of data collection, where Goldthorpe believes that there is the greatest weaknesses of contemporary ethnography.

But this is not the only position. Other authors (cf. for an introduction: Abell 2001b) maintain that in qualitative research with "small numbers», it is necessary to apply narrative methods that are distinct from the tradition of quantitative research. The reference to the importance of narrative, however, is of a methodological nature, and not theoretical or ontological: from an explanatory viewpoint narrative is considered as method (Kiser 1996, 249). Some recent developments pay particular attention to procedures for building up analytical narratives, in which qualitative analysis encounters logical analysis and the resources offered by formalisation. Abell's comparative analysis (1987; 2001a), Ragin's comparative qualitative analysis (2000), the analytic narratives project (Bates et al. 1998) and the analysis of sequences (Abbott 1995) are possibly some of the best-known examples. The methodological nature of the reference to narrative leads one to consider the need for qualitative research to tackle the same problems as quantitative research, even though they reach different solutions. It does not however lead to these problems being denied or ignored. All in all, also qualitative studies that refers to mechanismbased explanation specificy the generative process of the empirically observed relationship, though clearly not using the terms and concepts that are typical of quantitative research (cf. for example, Kalyvas 1999). Here too it is in any case necessary to discover the mechanisms and processes that in turn produce certain regularities (Little 198, 238).

To sum up, analytical sociology does not defend the idea of generative causality or causal realism so much, or only, on the epistemological level, but attempts to translate it into practical methodological suggestions and into examples of empirical research. The study of social mobility and inequalities increasingly make use of this perspective (Gambetta 1987; Goldthorpe 2000; Bianco 2001). The dynamic analysis of the effects of social networks has by now been developed and consolidated in the analysis of diffusion, contagion and imitation (cf. Hedström 1994; Valente 1995). Works on the microfoundations of cooperation in workgroups are one of the most inspiring examples of mechanisms-based explanation (Petersen 1992 and 1994). Laboratory experiments on collective action have made it possible to isolate, with a certain degree of precision, mechanisms for the social regulation of trust and the role of interpersonal communication in facilitating collective action (Bicchieri 2002). The literature on computer simulation focusing on the perspective of generative mechanisms has undergone stunning developments over the past ten years (Macy and Willer 2002). The study of indi- 
vidual careers and, more in general, the approach that considers the transitions of individuals or super-individual units between discrete states has now reached a remarkable level of theoretical precision and empirical detail, with consolidated applications and cumulative results (Blossfeld and Rowher 1995). Researches on the micro-foundations of collective violence provide perfect examples of mechanisms-based explanation in qualitative research (Kalyvas 1999). And these are only some of the best-known examples that have taken hold in recent debate.

\section{Analytical sociology: some leading principles}

Authors who refer to analytical sociology share two main objectives, which are closely linked to each other. The first concerns the creation of an analytical approach to sociological theory, while the second concerns the search for integration of theory and research. Due to space limitations, we shall look only at the first objective, deferring discussion of the second (cf. Barbera 2004).

The idea of an analytical approach to sociological theory may be clarified by identifying the main characteristics of the notion of «social mechanism» (Hedström and Swedberg 1998, 25; Goldthorpe 2000, 151; Stinchcombe 1993, 25; Pawson 2000, 67; Elster 1998, 45). Earlier on, we defined a «social mechanism» as a micro-process that explains how, in certain contexts, the macro-phenomenon observed is generated. We can now go into greater depth and identify three particularly important dimensions of this definition:

1) Mechanisms as causal processes;

2) Mechanisms as multilevel theories;

3) Mechanisms as formal models.

These are fairly general dimensions which need to be discussed in some detail here. These are also non-exclusive characteristics of mechanisms-based explanation, for they are also to be found in other currents of contemporary sociology. What makes them different is that analytical approaches are characterised by close interaction between these dimensions, as well as by an attempt to develop them in an explicit manner, aiming to achieve integration between theory and empirical research.

\subsection{Mechanisms as causal processes}

The first dimension of analytical approaches concerns the idea of causal or generative process and has in part been mentioned with reference to the relationships between analytical sociology and quantitative research. In this regard, Peter Hedström (2001) points out two main traditions of causal analysis in sociology: the first is the analysis of causal effects, which aims to establish the existence and/or relevance of certain causal effects between the independent 
variable(s) X and the dependent variable(s) Y. As Hedström maintains: «In this case the typical questions are: 'What are the probabilities that the values of $\mathrm{Y}$ will vary with variations in $\mathrm{X}$ (all factors being equal)?' And also "What effect does operation or process $\mathrm{X}$ have on the variable Y?» Hedström (ibid) refers here to the fact that the analysis of causal effects has come about in two traditions of causal analysis: causation as a "robust dependence» and "causation as consequential manipulation». In the first case, causality comes from statistical control of the effects of the intervening variables, while in the second case the causality is inferred by comparing the "treated» units with the «non treated» ones, all other factors being equal ${ }^{12}$.

The second tradition - that of the analysis of causal processes - on the other hand, concerns the identification of the causal process or mechanism that produces the relationship empirically observed between $\mathrm{X}$ and $\mathrm{Y}$. In this case the typical question is: "What process or mechanism has generated the effect of X on Y?» (Hedström 2001, 2). This tradition has its main proponents in the authors of analytical sociology; the perspective of causal processes thus undertakes to model and test the mechanism or process that generates the relationship between $\mathrm{X}$ and $\mathrm{Y}$. One is unlikely to explain a macro-phenomenon without hypotheses, models and data about the processes that have produced the empirical association being observed.

The narrative specification of the generative process, it must be said, is not simply equivalent to the identification of the mechanism. It is not enough to "narrate» a process or a sequence of events in temporal order to be able to isolate a generative mechanism: "[...] to have a narrative account of a sequence of historical events is not the same thing as having a theoretical account [...]» (Goldthorpe 2000, 59, c.m.). Elster, for example, distinguishes between causal mechanisms and assertions concerning the causes. It is often believed that by describing the cause or the causal series one has also identified the mechanism, but this is not the case (Elster 1989). It must actually be possible to apply the causal mechanism to other phenomena, which means that the mechanisms cannot be deduced from a description of the causal sequence of the particular phenomenon being examined. In other words, the mechanism is more general than the empirical phenomena to which it is applied.

\subsection{Multilevel theories: analytical supremacy and theoretical supremacy}

From the theoretical-substantive viewpoint, the social processes responsible for the empirically observed phenomenon are embedded in multilevel theoretical models. The idea of the multilevel theory refers to the coexistence of

12. For systematic discussion, see: Goldthorpe [2000, chap. 7]. Lieberson [1985] maintains that the model of causality as "robust dependence», especially in developments of multivariate techniques of data analysis, actually attempts to approximate the experimental situations that are typical of causality as "consequential manipulation». See also Sørensen [1999]. 
at least two analytical levels: micro and macro ${ }^{13}$, for which possible causal links are sought (Abell 2003) ${ }^{14}$.

The celebrated Coleman Boat - in other words, the graphic representation in the form of a «boat» of macro-micro-macro relationships ${ }^{15}$ - clearly illustrates the matter (see Figure 3). The diagram shows a system on two levels of abstraction, and the arrows that connect the levels indicate the direction of the explanation, from the explanans towards the explanadum. Four relationships are highlithed - macro-micro, micro-micro, micro-macro and macromacro- and the aim of the "boat» is to translate the direct macro-macro relationships into a causal process macro-micro-macro.

In this perspective, the macro-micro distinction is analytical and not empirical: micro does not correspond to the physical individual, nor does macro refer to «society». Rather, the micro-level is that of the system of interaction/interdepence - which may refer to individual and/or collective actors - and to their social relations, spatial configuration, and time ordering of interaction, while the macro-level concerns some sort of additive aggregation or non-additive -i.e. emergent - effect. The level of significant emergence or aggregation depends on the objectives of the study. The macro level may sometimes correspond to some form of phenomenon at the population or sub-population level — such as a rate of inter-generational mobility (Goldthorpe 2000) or an association between a particular class structure and a certain level of industrial conflict-, but it may also simply refer to a phenomenon which is not definable by reference to any single member of the interaction system (Coleman 1990, 5; Hedström 2005).

In analytical sociology, multilevel theories have strong microfoundations, but they are not microreductionist: reduction aims to eliminate theory B (e.g. sociology) and replace it with theory A (e.g. psychology), maintaining the same predicative field as theory B (cf. Udehn 2001 p. 335-336). Microfoundation,

13. To avoid confusion, it is worth pointing out that the "micro» level refers to a system of interaction and interdependence between the actors, and thus includes non-individual properties (social networks, spatial location, temporal organisation of actions).

14. This position already characterises developments in the micro-macro debate in sociology [Alexander et al. 1987], the most meticulous considerations on the individualism-holism debate [Udehn 2001], and the comparison of simulative methods and sociological theory [Macy and Willer 2000]. This perspective, called "weak methodological individualism», has been defined in a number of ways, aptly summarized in Udehn [2001].

15. The famous Coleman Boat was not actually invented by Coleman. A previous explicit version can already be found in McClelland $[1961,47]$. In the 1960s, David McClelland taught at Harvard and used the macro-micro-macro diagram during his classes. In that period, Siegwart Lindenberg was a student at Harvard and it was there that he learnt about the chart. In 1977, Lindenberg wrote an article in German - which has never been translated into English - that elaborated the analytical potential of the chart, even though without representing it in graphic form. In 1981, Coleman organised a seminar in Berlin on the problem of micro-macro relationships, and invited Lindenberg. It was then that Lindenberg showed McClelland's chart to Coleman, who adopted it and made it famous [Siegwart Lindenberg, personal communication with the author]. 


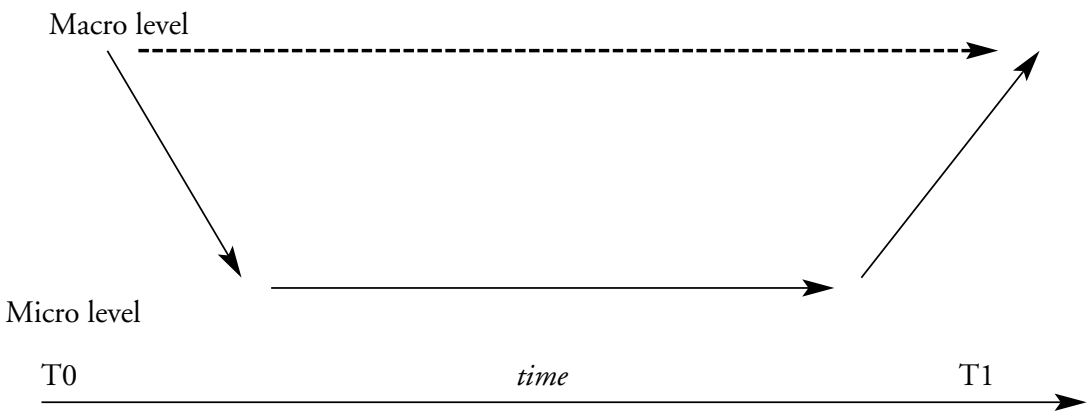

Figure 3. Macro-micro-macro relationships in the Coleman chart.

on the contrary, only requires a macro-phenomenon to be explained by means of some generative mechanism at the level of the action system. In other words, it only calls for social causality (macro-macro) not to be founded, irrespective of the processes at the level of social action and interaction (macro-micromacro) $)^{16}$.

The emphasis on the microfoundation of macro phenomena places precise logical constraints on the choice of the micro theory used, as well as on the criticisms levelled against it. If the explanandum is a macro-phenomenon, it follows that the individual is not, as such, their object (Boudon 1984) and the micro model used must therefore be: «as simple as possible and as complex as necessary» (Lindenberg 1992, 6). This qualifies the recourse to theories that are abstract and, at the same time, realistic: theories that focus on the mental states (desires, beliefs, perceived opportunity and information), on the principles that organise attention and cognition (frames and good reasons), on learning processes and, in general terms, on those elements that make social action comprehensible in intentional terms. The complexity and the realism of the model - both important elements in any sociological realistic explanationmust therefore consider that the ultimate aim of sociological explanation is some macro phenomenon and not the individual action itself. This implies a clear and precise distinction between the analytical supremacy and theoretical supremacy (Wippler and Lindenberg 1987): the former indicates the macrolevel on which the problem to be explained is located, while the second refers to the explanatory potential of the micro-theory employed. To analyse macro-

16. Microfoundation does not only analyse the actions of physical individuals, but applies the concept of the action unit to super-individual entities. Indeed, many empirical studies that tend towards mechanisms-based explanation have super-individual actors as their subject: the spread of trade unionism in Sweden [Hedström 1994], the strategic interaction between politicians and social actors [Scharpf 1997], or collective protest movements and revolutions [Opp 1998]. 
phenomena analytical sociology uses a simple and realistic microfoundational theory, the complexity of which is a function of its ability to explain (and not just to predict) the macro-phenomenon. The family of micro models used by analytical sociology thus requires a difficult balance between realism and abstraction, between the analytical supremacy of the macro-phenomena and the theoretical supremacy of the micro-processes, between the construction of simple models and the need to direct the study towards a genuine explanation of the phenomenon and not just towards predictive objectives (Hedström 2005). This leads to the third crucial characteristic of analytical sociology.

\subsection{Formal theories and models}

The third dimension of analytical approaches concerns the idea of models or formal theories. Models have a good level of analytical power: in other words, starting out from a limited number of information inputs, the theories used by analytical sociology generate many hypotheses (Heckathorn 1984). For example, a theory that needs detailed information on the emotional experiences and psychological idiosyncrasies of the actors has less analytical power -all other things being equal — than a theory that «works» only by reconstructing the situational logic (informations, desires, believes, opportunities) of social actors. For historical reasons, sociology has always looked with suspicion at the use of theories with great analytical power (Boudon and Bourricaud 1986). The perspective of mechanisms-based explanation, on the contrary, maintains the need to proceed with empirical analysis using models that have a suitable amount of analytic power ${ }^{17}$.

The emphasis on analytic power has a further consequence: models and formal theories do not apply to any situation in particular and have no claim to be universal, as Boudon maintains (Boudon 1984). So models are not descriptively complete, but they do select a set of characters and dimensions that can be useful for analysis.

The definition of the parameters of the model then follows two paths: in the first, the specification of the models comes from the concrete space-time conditions to which they apply (e.g.: bureaucracy in eighteenth-century France, the relationship between urban development and small enterprises in central Italy from 1920 to 1970 , the organisation of the local welfare system in the leading European capitals from 1970 to 1990). In the second meaning —which is preferred by authors of analytical sociology - the specification of the model is produced by abstract conditions of validity. Kiser $(1996,258)$, for example, shows how in the presence of inadequate communication and transport infrastructure and a low level of development of techniques for recording payments,

17. It may be important to note that these are mainly models built on the basis of locally relevant axioms, and thus obtained through empirical generalisations, and not through postulates built merely on a logical basis [for an example, cf. Granovetter 1973, and for a defence of this position: cf. Boudon 1984]. 
it is likely that problems of monitoring and control will appear in the relationship between State and citizens. This provides an incentive for the privatisation of tax-collection organisations and slows down the development of a wage-earning class employed by the State. Recourse to abstract conditions (or rather, the shift from conditions of concrete validity to abstract conditions) increases the transferability of the argument. Kiser and collaborators applied the model summarily referred to above to explain forms of tax collection in very different concrete contexts, such as in contemporary developing countries. The specification of abstract conditions of validity facilitated the transferability of the mechanism and thus increased the scope of the explanation.

In short, however they are defined, models remain an instrument and not the ultimate end of the theory: models are evaluated more than anything in terms of their ability to explain. From this point of view, the worry that the systematic use of models involves a defence of theory to the detriment of the explanation of the phenomenon is certainly excessive. This may happen, as in the case of neoclassical economics, when the model hiddens a strong theory agreed upon by a community of scholars, or a "paradigm». But this certainly is not the case of sociology, which is characterised by a whole range of explanatory theories which provide analytical sociology with a tool-kit apt to pursue sound sociological explanations.

\section{Conclusions}

I have attempted to illustrate the principles and objectives of a theoretical and research perspective that is asserting itself with increasing awareness and authority in current debates. In the 1990s, after the seminal works of Boudon, Coleman and Elster, the concept of social mechanisms explanation was adopted by authors involved in empirical research, who made important criticisms of the prevalent trends in today's social research and theory. Together with the expression "social mechanisms» appears that of analytical sociology. Analytical sociology tends to set out fairly clear borders with contemporary «social theory», with radical post-modernism, and with the creation of concise, allusive images of «society». Criticism of quantitative and qualitative studies aim to ensure better integration between social research and theory, and to achieve better complementarity between the various theoretical and empirical approaches.

The interaction between description and explanation, the focus on multilevel theories, the distinction between analytical supremacy and theoretical supremacy, the search for relationships between micro-processes and macrophenomena, the limited validity of theories, the preference for conditions of abstract validity and for theories that have analytical power, the integration between sociological theory and empirical research: if nothing else, these principles and objectives mark the borders of analytical sociology and, as a result, they define its scope and its limits. Indeed, the wish to define in detail one's own borders — and thus one's own limits - leads back to the idea that a cau- 
tious approach to what one can and cannot explain is a sign of disciplinary maturity.

Empirical research and the theoretical considerations inspired by the perspective of social mechanisms - which therefore attempt to model and empirically test the generative processes behind the production of the phenomenon to be analysed - show that the discussions about the impossibility of sociology being a social science are very similar to those models devised by some physicists to demonstrate that bumble bees cannot fly (Goldthorpe 2000, 18, note). To deny the validity of these arguments, it is not necessary to create other ones - one need only open one's eyes and look out of the window ${ }^{18}$.

\section{Bibliography}

Аввотт, A. (1995). «Sequence Analysis». Annual Review of Sociology, vol. 21, p. 93-113. Abell, P. (1987). The Sintax of Social Life. Oxford: Clarendon Press.

- (2001a). "On the Failure of Social Theory». British Journal of Sociology, 51, 4, p. $739-750$.

- (2001b). «Causality and Low-Frequency Complex Events: The Role of Comparative Narratives». Sociological Methods and Research, 30, 1, p. 57-80.

- (2003). "On the Prospects for a Unified Social Science: Economics and Sociology». Socio-economic Review, vol. 1. no. 1, p. 1-26

AleXANDER, J.C. et al. (1987). The Micro-Macro Link. University of California Press. BÄCKMAN, O.; EDLING, C. (1999). «Mathematic Matters: on the Absence of Mathematical Models in Quantitative Sociology». Acta Sociologica, 42, p. 69-78. BARBera, F. (2004). Meccanismi sociali. Elementi di sociologia analitica. Bologna: Il Mulino.

BATES, R. et al. (1998). Analytic Narratives. Princeton: Princeton University Press. BiANCO, M.L. (2001). L'Italia delle diseguaglianze. Rome: Carocci.

BICCHIERI, C. (2002). «Covenants without swords. Group identity, norms, and communication in social dilemmas». Rationality and Society, 14, 2, p. 192-228.

Blossfeld, H.-P.; RoHWer, G. (1995). Techniques of Event History Modelling: New Approaches to Causal Analysis. Mahwah: Erlbaum.

Blossfeld, H.P.; Prein, G. (ed.) (1998). Rational Choice Theory and Large-Scale Data Analysis. Boulder: Westview Press.

Boudon, R. (1976). "Comment on Hauser's Review of Education, Opportunity, and Social Inequality». American Journal of Sociology, 81, p. 1175-87.

- (1979a). La logique du social. Paris: Libraire Hachette.

- (1979b). «Generating Models as a Research Strategy». In: MerTON, R.; ColEMAN, J.S.; Rossi, P. (ed.). Qualitative and Quantitative Social Research. The Free Press, p. 51-64.

- (1984). La place du désordre. Paris: Puf.

- (2002). «Sociology that Really Matters». European Sociological Review, 18, p. 371-378.

Boudon, R.; Bourricaud, F. (1986). Dictionnaire Critique de la Sociologie. Paris: Puf, 2nd ed.

18. This is what Max Steuer did recently in The Scientific Study of Society [2002]. 
CHERKAOUI, M. (2000). «La stratégie de mécanismes générateurs comme logique de l'explication». In: BACHELER, J. (ed.). L'acteur et ses raisons. Mélanges pour Raymond Boudon. Paris: Puf, p. 131-151.

Coleman, J.S. (1964). Introduction to Mathematical Sociology. New York: The Free Press.

- (1982). The Asymmetric Society. New York: Syracuse University Press.

- (1986). «Social Theory, Social Research and a Theory of Action». American Journal of Sociology, 91, p. 1309-1335.

- (1990). Foundations of Social Theory. Cambridge: The Belknap Press of the Harvard University Press.

DenZin, N. (1990). «The Long Good-bye: Farewell to Rational Choice Theory». Rationality and Society, vol. 2, no. 4, p. 504-507.

Edling, C. (2002). «Mathematics in Sociology». Annual Review of Sociology, 28, p. $197-220$.

ELSTER, J. (1983). Explaining Technical Change. Cambridge: Cambridge University Press.

- (1985). Making Sense of Marx. Cambridge: Cambridge University Press.

- (1989). Nuts and Bolts for the Social Sciences. Cambridge: Cambridge University Press.

- (1998). A Plea for Mechanisms. In: Hedstrom, P.; Swedberg, R. (eds.). Social Mechanisms. Cambridge University Press, p. 45-73.

FlyvBJERG, B. (2001). Making Social Science Matter. Cambridge: Cambridge University Press.

GambetTa, D. (1987). Were they Pushed or Did they Jump? Cambridge: Cambridge University Press.

Goldthorpe, J.H. (2000). On Sociology. Oxford: Oxford University Press.

- (2004). «Sociology as Social Science and "Cameral» Sociology». European Sociological Review, 20, p. 97-105.

HeCKathorn, D.D. (1984). «Mathematical Theory Construction in Sociology: Analytic Power, Scope and Descriptive Accuracy as Trade-Offs». The Journal of Mathematical Sociology, 10, p. 295-323.

Hedström, P. (1994). «Contagious Collectivities: On the Spatial Diffusion of Swedish Trade Unions, 1890-1940». American Journal of Sociology, 99, 5, p. 1157-79.

- (2001). Strategies for Linking Theories and Data: on the Explanatory Sociology of Aage B. Sorensen. Working Paper no. 7. Department of Sociology, University of Stockholm.

- (2005). Dissecting the Social: On the Principles of Analytical Sociology. Cambridge: Cambridge University Press (forthcoming).

Hedström, P.; SwedberG, R. (eds.) (1998). Social Mechanisms. Cambridge: Cambridge University Press.

KaLYVAS, S. (1999). «Wanton and Senseless? The Logic of Collective Massacres in Algeria». Rationality and Society, 11, 3, p. 243-285.

King, G.; Kehoane, R.O.; Verba, S. (1994). Designing Social Inquiry. Princeton: Princeton University Press.

KISER, E. (1996). «The Revival of Narrative in Historical Sociology: What Rational Choice can Contribute». Politics and Society, 24, no. 3, p. 249-271.

LindenBerG, S. (1977). «Individuelle effect, kollektive Phänomene und das problem der transformation». In: EICHER, K.; HABERMEHL, W. (eds.). Probleme der erkläurung sozialen vernhaltens. Meisenheim am Glan: Anton Hain, p. 47-84.

- (1992). "The Method of Decreasing Abstraction». In: COlEMAN, J.S.; FARARO, T. (eds.). Rational Choice Theory: Advocacy and Critique. Newbury Park: Sage. 
LitTle, D. (1998). Microfoundations, Methods and Causation. New Brunswick and London: Transaction Publishers.

MaCY, M.W. (1993). «Backward-Looking Social Control». American Sociological Review, 58, 6, p. 819-836.

MACY, M.W.; WILlER, R. (2002). «From Factors to Actors: Computational Sociology and Agent-Based Modelling». Annual Review of Sociology, 28, p. 143-66.

MAHONEY, J. (2001). «Beyond Correlational Analysis: Recent Innovations in Theory and Method». Sociological Forum, vol. 16, n. 3, p. 575-593.

McClelland, D.C. (1961). The Achieving Society. Princeton: D. Van Nostrand Co. Merton, R.K. (1987). «Three Fragments from a Sociologist's Notebook: Establishing the Phenomenon, Specified Ignorance and Strategic Research Materials». Annual Review of Sociology, 13, p. 1-28.

Opp, K.D. (1998). "Can and Should Rational Choice Theory be Tested by Survey Research? The Example of Explaining Collective Political Action». In: BLOSSFELD, H.P.; Prein, G. (eds.). Rational Choice Theory and Large-Scale Data Analysis. Boulder: Westview Press, p. 204-230.

PawsOn, R. (1997). Realistic Evaluation. London: Sage Publications.

- (2000). «Middle-Range Realism». Arch. Europ. Sociol, XLI, 2, p. 283-325.

Petersen, T. (1992). «Individual, Collective and Systems Rationality in Work Groups: Dilemmas and non Market Solutions». Rationality and society, 4, no. 3, p. 332-355.

- (1994). "On the Promise of Game Theory in Sociology». Contemporary Sociology, 23, n. 4, p. 498-502.

Ragin, C.C. (1998). "Case-Oriented Research and the Study of Social Action». In: Blossfeld, H.P.; Prein, G. (eds.). Rational Choice Theory and Large-Scale Data Analysis. Boulder: Westview Press, p. 158-168.

- (2000). Fuzzy-set Social Science. Chicago and London: University of Chicago Press. RiCOLFI, L. (1984). Modelli dell'attore e analisi dei dati. Turin: Giappichelli.

SCHARpf, F. (1997). Games Real Actors Play: Actor-Centered Institutionalism in Policy Research. Boulder: Westview.

Sørensen, A.B. (1998). «Theoretical Mechanisms and the Empirical Study of Social Processes». In: Hedström, P.; SwedBerG, R. (eds.). Social Mechanisms. Cambridge: Cambridge University Press, p. 238-266.

- (1999). «Statistical Models and Mechanisms of Social Processes». Paper presented at the Annual Meeting of the Swedish Association of Statistics.

Steuer, M. (2002). The Scientific Study of Society. Kluwer Academic Publisher.

STinchCombe, A. (1993). "The Condition of Fruitfullness of Theorizing About Mechanism in Social Sciences». In: Sørensen, A.; SpILERMAn, S. (eds.). Social Theory and Social Policy. Essays in Honor of James S. Coleman. Westport: Praeger Publishers, p. 23-41.

UDEHN, L. (2001). Methodological Individualism. London: Routledge.

VAlente, T. (1995). Network Models of Diffusion of Innovations. Broasday: Hampton Press.

VAn Den Berg, A. (1998). «Is Social Theory Too Grand For Social Mechanisms?». In: Hedström, P.; SwedberG, R. (eds.). Social Mechanisms. Cambridge: Cambridge University Press, p. 204-237.

WiPPleR, R.; LindenberG, S. (1987). «Collective Phenomena and Rational Choice». In: AleXANDER, J.C. et al. The Micro-Macro Link. University of California Press, p. 135-152. 